\title{
Erratum to: Characterizing lentic freshwater fish assemblages using multiple sampling methods
}

\author{
Jesse R. Fischer • Michael C. Quist
}

Published online: 6 May 2014

(C) Springer International Publishing Switzerland 2014

\section{Erratum to: Environ Monit Assess \\ DOI 10.1007/s10661-014-3711-z}

The original version of this article unfortunately contained a mistake.

There was a part missing from table 2 in the original version of this article.

The complete table is given below.

The online version of the original article can be found at http://dx. doi.org/10.1007/s10661-014-3711-z.

\footnotetext{
J. R. Fischer

Department of Natural Resource Ecology and Management, Iowa State University,

339 Science II, Ames, IA 50010, USA

M. C. Quist

U.S. Geological Survey, Idaho Cooperative Fish and Wildlife Research Unit, Department of Fish and Wildlife Resources, University of Idaho,

Moscow, ID 83844, USA

e-mail: mcquist@uidaho.edu

Present Address:

J. R. Fischer $(\bowtie)$

North Carolina Cooperative Fish and Wildlife Research Unit, Department of Applied Ecology, North Carolina State University,

Raleigh, NC 27695-7617, USA

e-mail: jessefischer@gmail.com
} 


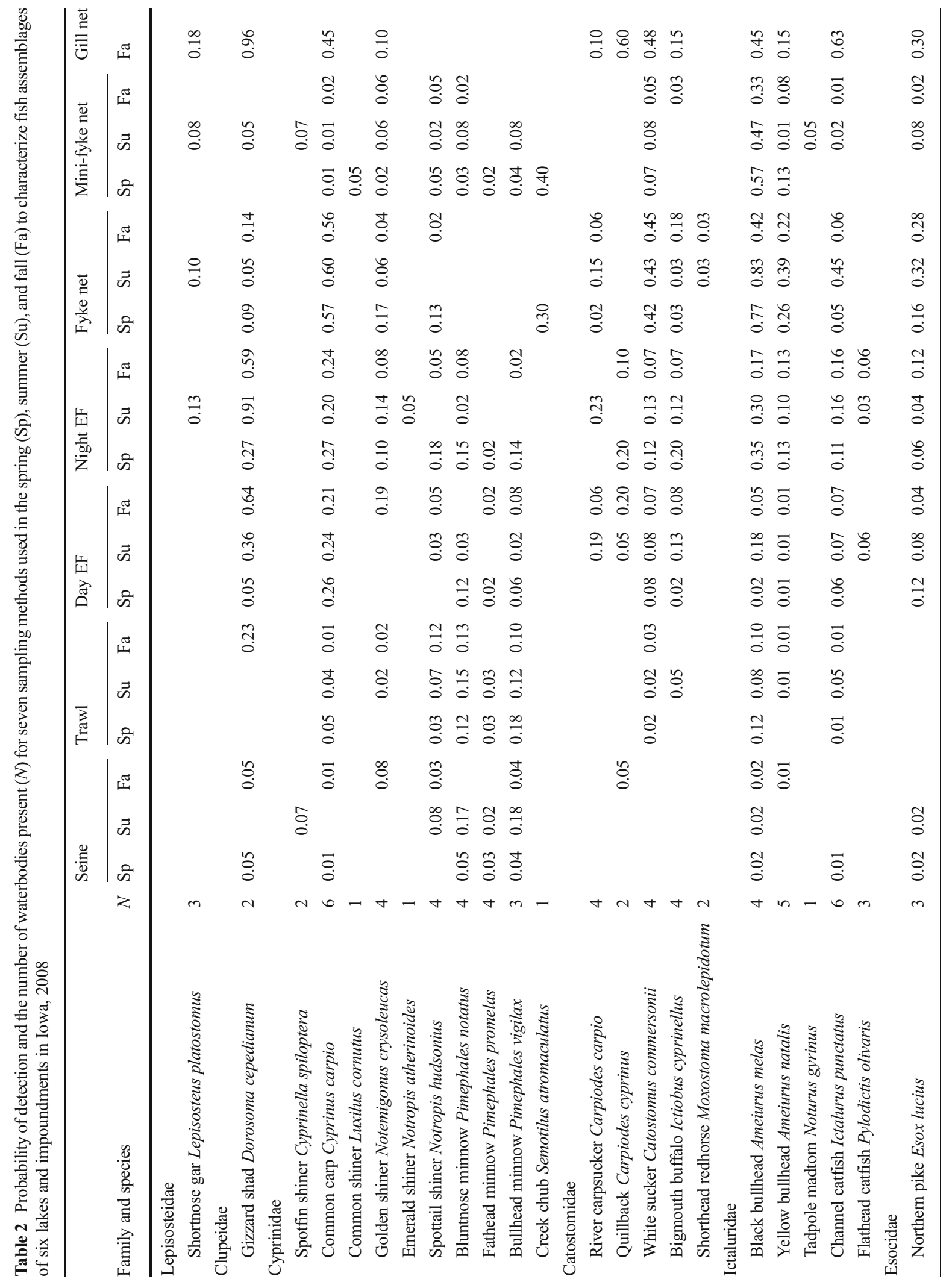




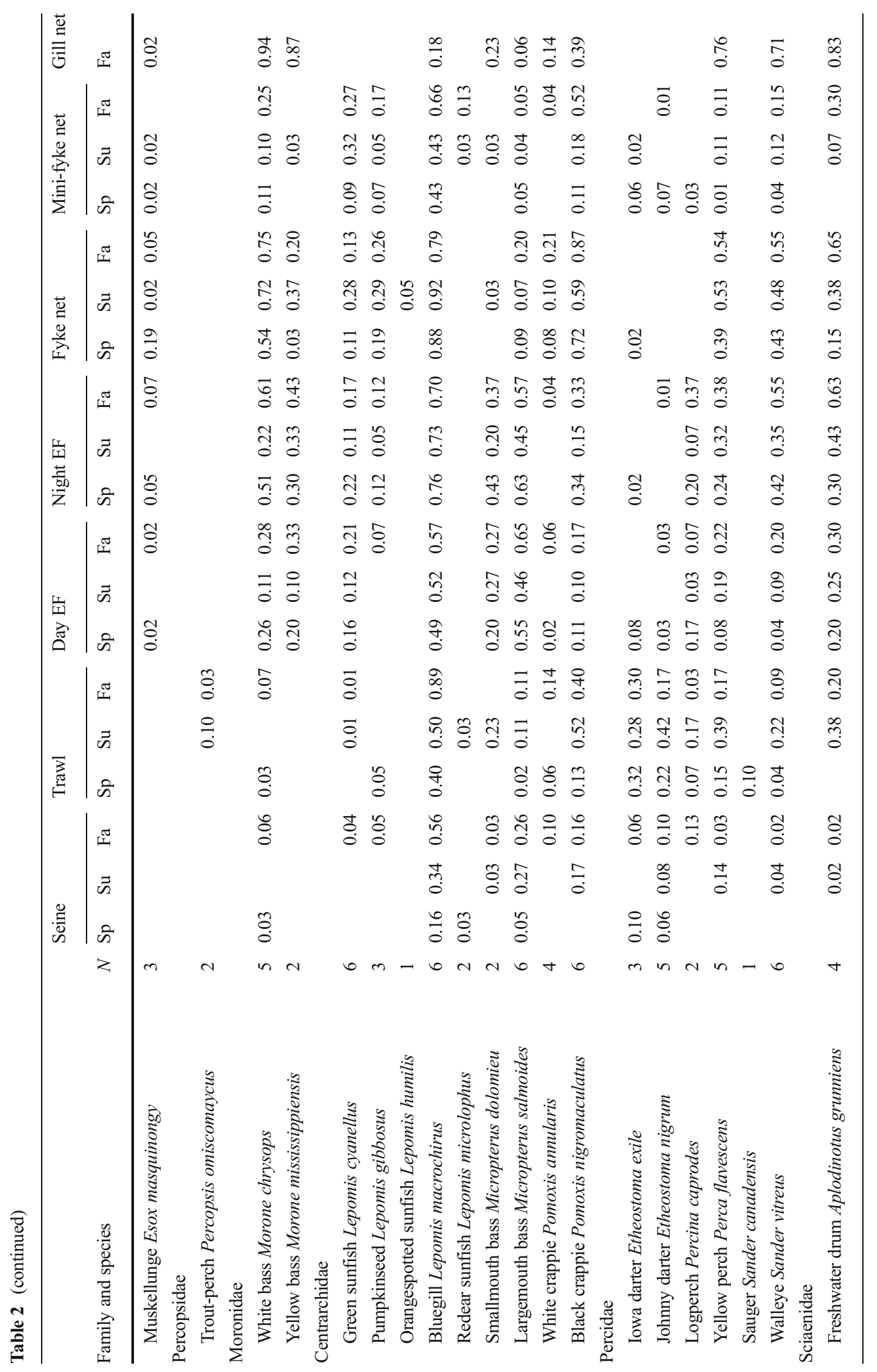

